EGYPTIAN INFORMATION Magazine CompuNet

Specialized Scientific Cultural Referred Journal For Authorized Scientific Articles

Issued By the Egyptian Society for Information Systems and Computer Technology (ESISACT)

Approved Issuance and Licensed by Higher Journalism Council dated $5 / 11 / 1998$

President of the Editorial Board Prof. Dr.

Mohamed M. El Hadi

Vice President Prof. Dr.

Alaa El Din M. El Ghazali Chief Editor Sayed Alhady

Art Director

Dr. Abdulkareem.M

Director General

Ahmed Qotb

Editorial Staff

Dr. Ahmed Zidan

Dr. Enas Elshety

Dr. Hussein Moselhy

Correspondences

22 Khayrat St.(Floor No. 3, Appt. No. 5), El-Sayedda Zeyab, Cairo, ARE

P. O. Box No. (2083), Cairo 11511, Egypt

E-mail: esisact-08@yahoo.com melhadi@yalla.com

Web Sites: www.esisact.org.eg www.facebook.com/esisact

\section{Scientific Consultative Committee Members}

Prof. Dr. Abdelbadeeh M. Salem

Prof. Emeritus of Computer Science,

Faulty of Computers and Information, Ain Shams University

Prof. Dr. Abdellatif Elgazzar

Prof. emeritus of Educational Technology, Girls College, Ain Shams University

Prof. D. Alaa El-Din M. El Ghazali

Prof. of Information Systems and President of Sadat Academy for Management Sciences

Prof. Dr. Gamal M. Aly

Prof. of Software Engineering, Faculty of Engineering, Ain Shams University

Prof. Dr. Mohamed Abdelhameed Ahmed

Prof. Emeritus of Educational Technology,

Faculty of Education, Helwan University

Prof. Dr. Mohamed Badr Senousy

Prof. Emeritus of Computer Science, Sadat Academy for Management Sciences

Prof. Dr. Mohamed Fahmi Tolba

Prof. Emeritus of Computer Science, Faculty of Computers and Information, Ain Shams University, President of Scientists

Syndicate \& Member of El Shoura Concil

Prof. Dr. Mohamed Fathy Abdelhady

Prof. Emeritus of Library and Information Science, Faculty of Arts, Cairo University

Prof. Dr. Mohamed Magdy Kabeil

Prof. Emeritus of Computer Science, Sadat Academy for Management Silences

Prof. Dr. Mohamed M. El Hadi

Prof. Emeritus of Information Systems, Sadat Academy for Management Sciences

Prof. Dr. Nashaat El Khamisy Mohamed

Prof. Emeritus of Computer and Information Systems, Sadat Academy

Prof Dr. Sayed M. Abdlwahab

Prof. Emeritus of Computer Science, Sadat Academy for Management Silences

Prof. Dr. Sherif Kamel Shahin

Prof. and Head of Library and Information Dept., Faculty of Arts, Cairo University 